\title{
Two patients with intestinal failure requiring home parenteral nutrition, a NOD2 mutation and tuberculous lymphadenitis
}

\author{
Holger Schäffler ${ }^{1}$, Matthias Teufel ${ }^{2}$, Sabrina Fleischer ${ }^{2}$, Chih-Jen Hsieh ${ }^{3}$, Julia-Stefanie Frick ${ }^{4}$ and Georg Lamprecht ${ }^{\text {* }}$
}

\begin{abstract}
Background: Mutations in the NOD2 gene are a significant risk factor to acquire intestinal failure requiring home parenteral nutrition. Tuberculous lymphadenitis is the main manifestation of extrapulmonary tuberculosis. Defects in the innate immunity, including NOD2 mutations, may increase the risk for acquiring infections caused by M. tuberculosis. An association of intestinal failure, mutations in the NOD2 gene and tuberculous lymphadenitis has not been described before.

Case presentation: We report of two patients with intestinal failure secondary to mesenteric ischemia. Both patients presented with fever and weight loss while receiving long term home parenteral nutrition. Both of them were found to have mutations in the NOD2 gene. Catheter related infections were ruled out. FDG-PET-CT scans initially obtained in search for another infectious focus that would explain the symptoms unexpectedly showed high FDG uptake in mediastinal lymph nodes. Direct or indirect evidence proved or was highly suggestive for tuberculous lymphadenitis. Intravenous tuberculostatic therapy was started and led to a reversal of symptoms and to resolution of the lesions by FDG-PET-CT.
\end{abstract}

Conclusion: Mutations in the NOD2 gene may put patients both at an increased risk for acquiring M. tuberculosis infections as well as at an increased risk of intestinal failure after extensive intestinal resection. Thus we suggest to specifically include reactivated and opportunistic infections in the differential diagnosis of suspected catheter related infection in patients with intestinal failure who carry mutations in their NOD2 gene.

Keywords: NOD2, Intestinal failure, Tuberculous lymphadenitis, Catheter related blood stream infection

\section{Background}

Tuberculous lymphadenitis is the most frequent site of extrapulmonary tuberculosis. About $20 \%$ of all TBC cases in the US are extrapulmonary. From this group, about $40 \%$ are tuberculous lymphadentis [1]. Detection of $M$. tuberculosis is mainly via the innate immune system by extracellular or intracellular pattern recognition receptors (PRR) such as toll-like receptors (TLR) and nucleotidebinding oligomerization domain receptors (NOD) [2-4]. Mutations in specific TLR genes were found to be associated with susceptibility to TBC $[5,6]$.

Clinical relevance of mutations in the NOD2 gene arises from their association with Crohn's disease [7-10].

\footnotetext{
* Correspondence: georg.lamprecht@med.uni-rostock.de

1 Division of Gastroenterology, Department of Medicine II, University of

Rostock, Ernst-Heydemann-Str. 6, D-18057 Rostock, Germany

Full list of author information is available at the end of the article
}

In 2001, a link between mutations in the NOD2 gene and Crohn's disease was first established independently by two different groups $[11,12]$. However, the exact function of NOD2 is still under debate [13]. Besides Crohn's disease, other disease entities seem to be related to mutations in the NOD2 gene like GvHD [14-16], acute septicemia [17], spontaneous bacterial peritonitis in liver cirrhosis $[18,19]$ and worsened outcome after intestinal transplantation [20]. Mutations in the NOD2 gene and an increased susceptibility for infectious diseases have been reported in the literature [21]. NOD2 is also thought to be an important receptor in recognizing $M$. tuberculosis, because on the one hand both the receptor and the pathogen are intracellular and on the other hand the cell wall of $M$. tuberculosis contains peptidoglycan, which is one of the ligands of NOD2 [22]. However, the role of NOD2 in tuberculous lymphadenitis has not been 
studied yet. To this end a recent study has described a new SNP in the NOD2 gene as a possible risk factor for pulmonary tuberculosis in the Chinese Han population [23]. In another study it was reported that genes in the NOD2 signaling pathway are associated with susceptibility to infections with Mycobacterium leprae in China [24].

Short bowel syndrome (SBS) and intestinal failure requiring long term home parenteral nutrition (HPN) are rare heterogeneous clinical conditions in which extensive parts of the intestine have been removed surgically. The main causes of short bowel syndrome in adults are Crohn's disease, intestinal ischemia, volvulus, ileus, desmoid tumors and trauma [25]. Recently we have described an increased frequency of NOD2 mutations in SBS patients without underlying Crohn's disease [26]. Infections associated with intestinal failure requiring home parenteral nutrition are mainly catheter-related [27,28].

Here we describe two individuals with short bowel syndrome, mutations in the NOD2 gene and tuberculous lymphadenitis. This is a clinically important finding because in a HPN patient intermittent fever, the key symptom of tuberculous lymphadenitis, usually indicates catheter related blood stream infection. To our best knowledge, this is the first case report linking these clinical entities together.

\section{Materials and methods}

Genotyping of patients was performed as part of a larger study in a cohort of short bowel patients, which was approved by the Ethics Committee of the University of Tuebingen $(022 / 2011 \mathrm{BO} 2)$. The patients gave written informed consent. The three major mutations in the NOD2 gene (SNP 8; R702W, NCBI reference SNP ID: rs2066844 and SNP 12; G908R, NCBI reference SNP ID: rs2066845 and 3020insC, SNP 13; 1007 fs, NCBI reference SNP ID: rs2066847) were detected in genomic DNA extracted from whole blood as described previously [26].

Direct Nucleic Acid Amplification Test (NAAT) to detect $M$. tuberculosis complex DNA was performed using the ProbeTec ET DTB (DTB) (Becton-Dickinson). For identification of Mycobacterium tuberculosis complex species GenoType MTBC (Hain) was used according to manufacturer's instructions. As gold standard culture techniques using 2 solid and BACTEC ${ }^{\mathrm{mm}}$ MGIT 960 liquid broth were applied. For direct susceptibility testing we used the BACTEC ${ }^{\mathrm{mm}} M G I T^{\mathrm{m}}$ 960. As interferon-gamma-release assay we used the QuantiFERON-TB ${ }^{\circ}$ Gold In-Tube test (Cellestis) according to manufacturer's instructions.

\section{Case presentation}

\section{Patient 1}

Patient 1 is a 44 year-old Caucasian woman with intestinal failure. In 2008, she required surgical resection of most of her small intestine (except for $70 \mathrm{~cm}$ of proximal jejunum) and the right colon resulting in a duodenotransversostomy due to acute occlusion of her superior mesenteric artery. Total parenteral nutrition was initiated at the University of Tübingen intestinal failure outpatient clinic. The initial clinical course was dominated by numerous infectious complications, e.g. recurrent line infections $(05 / 2009,04 / 2010,02 / 2012)$, a liver abscess and an episode of acute cholecystitis in the absence of cholelithiasis, which was interpreted as another ischemic episode in the splanchnic circulation (Figure 1).

Despite an extensive workup (including ultrasound and CT-scan) the etiology of the ischemic events could not be determined. The diagnosis of Takayasu Arteriitis was entertained because of diminished/absent peripheral pulses but vasculitis was neither found by histology in the resected specimens nor by PET-CT in the large vessels. Workup for a coagulation disorder revealed a heterozygous prothrombin mutation (G20210A). An antiphospholipid syndrome was ruled out and the JAK2-mutation was also not detected. A HIV test was negative.

Because of the severity of two acute episodes of arterial occlusion the patient was maintained on low dose steroids (Prednisolone $5 \mathrm{mg}$ ) and received long term anticoagulation with enoxaparin (Clexane) and later fondaparinux (Arixtra). Under this regimen, the patient did not develop another episode of intestinal or systemic arterial ischemia.

Genetically she was found to be heterozygous for the 1007 fs NOD2 mutation. In 2010, after two years of successful parenteral nutrition without any infectious complications the patient started to lose weight and had intermittent episodes of fever. The laboratory values showed an increased CRP value $(30.5 \mathrm{mg} / \mathrm{dl})$ and anemia $(6.7 \mathrm{~g} / \mathrm{dl})$. A catheter-related infection was excluded by repeated blood cultures. Another FDG-PET-CT was obtained addressing again the question of a large vessel vasculitis. Unexpectedly it showed for the first time an intensive uptake of the FDG tracer in three lymph nodes in the mediastinum. An interferon- $\gamma$-release assay was positive (Quantiferon ${ }^{\circ}$ ). A transbronchial biopsy of one of the lymph nodes revealed necrotic material and a granuloma by histology, highly suggestive for tuberculous lymphadenitis. M. tuberculosis-DNA was detected by PCR and cultures obtained from the lymph node also grew $M$. tuberculosis. Intravenous tuberculostatic therapy with Ethambutol, Isoniazid and Rifampicin was given for 4 months followed by Isoniazid and Rifampicin for another 8 months. The follow-up FDG-PET-CT after 7 months of therapy showed a significant size reduction and decreased FDG uptake of the lymph nodes in the mediastinum. The patient stayed on prophylactic therapy with Isoniazid until today, because she continued low dose steroids. 

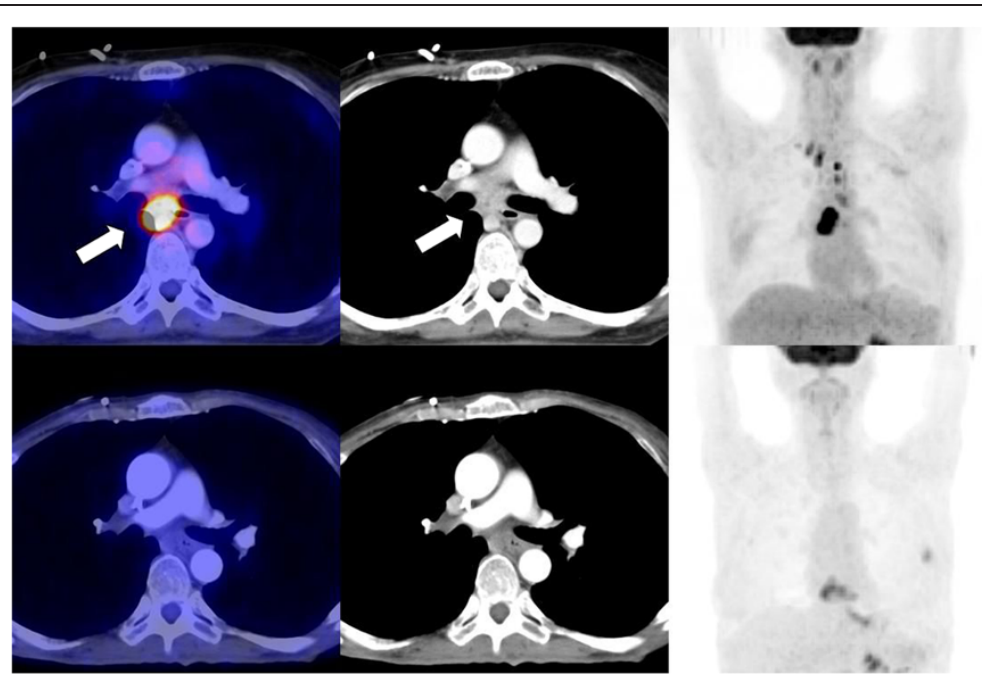

Figure 1 Patient 1. Upper row - before tuberculostatic therapy: High FDG uptake in an infracarinal lymph node (left panel: fusion images of PET/ $\mathrm{CT}$ ) correlating with central necrosis in the contrast enhanced CT (middle panel). Coronal MIP with high FDG uptake in several mediastinal lymph nodes (right panel). Lower row - 8 month follow up: No FDG uptake (left panel: PET/CT) and significant size reduction of the visualized lymph nodes (middle panel: ceCT). No pathological FDG uptake in the mediastinal lymph nodes on coronal MIP of PET (right panel).

\section{Patient 2}

Patient 2 is a 77 year-old Caucasian woman who had an infarction of the small intestine and right colon due to atherosclerotic occlusion of the superior mesenteric artery in November 2003. She required extensive resection of her small bowel, which resulted in a jejunotransversostomy with $20 \mathrm{~cm}$ of proximal jejunum. Total parenteral nutrition was started and was managed at the University of Tübingen intestinal failure outpatient clinic. In 2010 she developed fever, weight loss and night sweats. An elevated ESR and LDH were found. Repeated attempts to verify catheter related blood stream infection including numerous blood cultures, several rounds of empiric antibiotic therapy and an empiric exchange of the catheter had no sustained effect on these symptoms. A FDG-PET-CT scan was performed addressing a potential infectious focus other than the catheter. Unexpectedly it revealed PETpositive lymphadenopathy in the cervical region and in the mediastinum. An interferon- $\gamma$-release assay was negative (Quantiferon ${ }^{\circ}$ ). A bronchoscopic biopsy of the suspicious lymph node revealed granulomatous necrotizing lymphadenitis, but acid fast bacilli could not be stained. A specific pathogen could not be cultured and eubacterial PCR as well as PCR for M. tuberculosis were negative. The family history revealed that several relatives had suffered from tuberculosis. Based on the sum of indirect evidence the diagnosis of tuberculous lymphadenitis was made. Tuberculostatic therapy (Isoniazid, Rifampicin, Ethambutol and Levofloxacin) was applied intravenously for 6 months. The patient soon felt better and gained weight. Fever and anemia resolved, and the LDH and the ESR returned to normal values.
Regression of the enlarged and hypermetabolic lymph nodes was verified by another PET-CT-scan obtained 7 months after the initiation of specific therapy. One remaining small mediastinal lymph node was regarded as non-specific, (Figure 2).

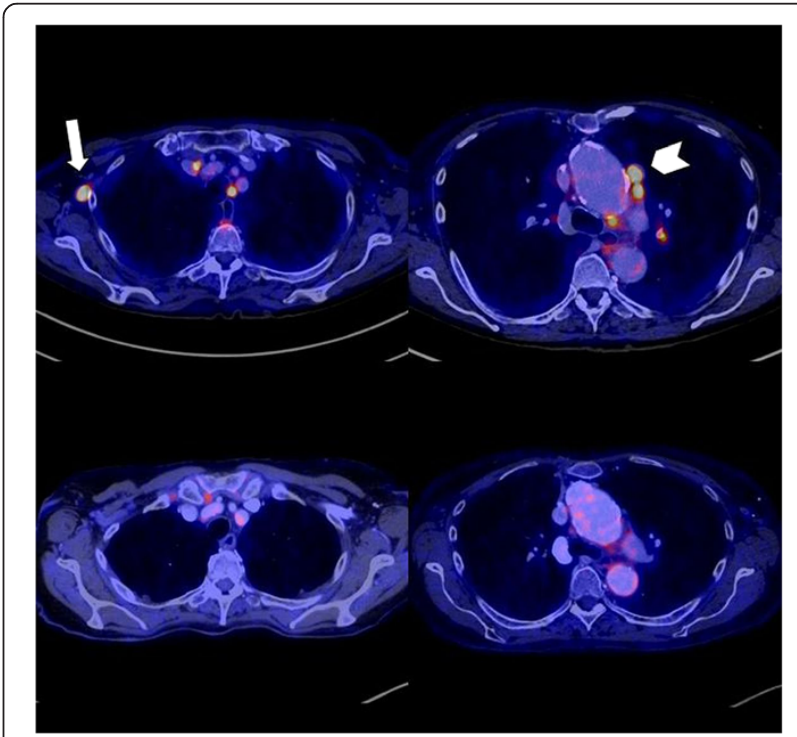

Figure 2 Patient 2. Upper row - before tuberculostatic therapy: high FDG uptake in several mediastinal and one right axillary (arrow) lymph nodes. Additionally, further lymph nodes with high FDG uptake, especially in the left paraaortal (arrow head) region. Lower row - 7 month follow up after initiation of tuberculostatic therapy: No FDG uptake in the right axillary lymph nodes and significant regression of FDG uptake of the paraaortal lymph nodes after therapy. All PET positive lymph nodes had a morphological correlate and showed a significant size reduction after therapy in contrast enhanced CT (not shown). 
The patient was found to be heterozygous for the R702W mutation in the NOD2 gene.

\section{Conclusion}

In patients with intestinal failure on HPN the occurrence of low grade fewer, night sweats, declining performance status, low albumin and sometimes increased bilirubin usually prompts the diagnosis of a line related infection. This is because about $30 \%$ of line related infections in this cohort do not present with typical symptoms of high grade fever and rigors upon start of a new infusion but rather with those atypical symptoms [28]. In addition line related infections are the most frequent complication in HPN patients occurring with a frequency between two episodes per year and one episode every three years [28]. Nevertheless the diagnosis of line related infection could not be firmly established in either of these patients and empiric therapy was not successful. Instead tuberculous lymphadenitis was diagnosed and successfully treated. Predisposition for acquiring or reactivating tuberculosis may have been facilitated by the fact that patients with SBS receiving long term HPN have an impaired immune response [29]. Furthermore patient 1 was receiving steroids over a prolonged period of time system. It must also be noted that patient 2 may have had an atypical mycobacterial infection. On the other hand, tuberculosis, especially tuberculous lymphadenitis, has not been recognized as a specific problem in intestinal failure patients on HPN yet. So how may these conditions be related other than by chance?

Both patients carried a mutation in the NOD2 gene (patient 1: 1007 fs, patient 2: R702W). NOD2 is an intracellular pattern recognition receptor which recognizes muramyl dipeptide (MDP) as part of peptidoglycan of the bacterial cell wall $[30,31]$. The cumulative incidence (homozygous, heterozygous and compound heterozygous) of mutations in the 3 major NOD2 SNPs (R702W, G908R and $1007 \mathrm{fs}$ ) is $13.6 \%$ in a cohort of healthy controls [7]. Recently we and others have reported an increased frequency of NOD2 mutations in SBS patients $[26,32]$. At present it is not clear, whether a defect in NOD2 signaling leads to an altered response to operative stress ultimately resulting in a SBS or whether intestinal adaptation to the SBS situation is diminished resulting in long term HPN [26].

M. tuberculosis is mainly recognized via PRR like TLRs and NOD2. Certain mutations in the TLR genes, e.g. TLR1 and TLR6 are associated with an increased risk of acquiring $M$. tuberculosis [5,6]. In one study, host cells after exposure to $M$. tuberculosis were sensing the microbeassociated molecular pattern (MAMP) using independent PRRs like NOD2 and TLR. The study showed, that these receptors were non-redundant and interacted with each other synergistically [33]. In addition monocytes from patients homozygous for the 1007 fs mutation (3020insC) show diminished TNF and IL-10 cytokine response after stimulation with $M$. tuberculosis compared to heterozygous or homozygous wild-type controls. A cohort study in 377 African Americans with tuberculosis found that certain SNPs in the NOD2 gene were associated with either resistance or susceptibility to tuberculosis [34]. Nevertheless NOD2 mutations have not been firmly established as a risk factor for tuberculosis and several studies argue against such a correlation $[35,36]$.

Thus, NOD2 mutations may be the common risk factor for both patients to develop intestinal failure requiring HPN and to acquire or reactivate tuberculosis, in these two cases tuberculous lymphadenitis. From a clinical point of view these two cases highlight the importance to search for alternative infectious complications other than line related blood stream infection in patients with SBS on HPN, including tuberculosis.

\section{Consent}

Written informed consent was obtained from both patients for publication of this Case report and any accompanying images. A copy of the written consent from both patients is available for review by the Editor of this journal.

\section{Abbreviations}

ESR: Erythrocyte sedimentation rate; FDG-PET: Fluordeoxyglucose positron emission tomography; GvHD: Graft-versus-host-disease; HPN: Home parenteral nutrition; IL: Interleukin; JAK2: Janus kinase 2; LDH: Lactate dehydrogenase; MAMP: Microbe-associated molecular pattern; NAAT: Nucleic Acid Amplification Test; NOD: Nucleotide-binding oligomerization domain receptors; PCR: Polymerase chain reaction; PRR: Pattern recognition receptor; SBS: Short bowel syndrome; SNP: Single nucleotide polymorphisms; TBC: Tuberculosis; TLR: Toll-like receptor; TNF: Tumor necrosis factor.

\section{Competing interests}

All authors declare that they have no competing interests.

\section{Authors' contributions}

$\mathrm{GL}$ and $\mathrm{HS}$ gathered the information about the two patients. $\mathrm{CH}$ performed the mutational analysis. MT and SF collected the data from the FDG PET CT scans and analyzed them. JSF completed the microbiological part in Material and Methods. GL and HS wrote the manuscript. All authors read and approved the final manuscript.

\section{Acknowledgments}

We would like to thank Dr. Christina Gilot, who helped us in the acquisition of the lab values of patient 1

\section{Author details}

'Division of Gastroenterology, Department of Medicine II, University of Rostock, Ernst-Heydemann-Str. 6, D-18057 Rostock, Germany. ${ }^{2}$ Department of Diagnostic Radiology, Eberhard Karls University Tübingen, Tübingen, Germany. ${ }^{3}$ 1st Medical Department, University of Tübingen, Tübingen, Germany. ${ }^{4}$ Institute of Medical Microbiology and Hygiene, University of Tübingen, Tübingen, Germany.

Received: 26 October 2013 Accepted: 20 February 2014

Published: 6 March 2014 


\section{References}

1. Peto HM, Pratt RH, Harrington TA, LoBue PA, Armstrong LR: Epidemiology of extrapulmonary tuberculosis in the United States, 1993-2006. Clin Infect Dis 2009, 49(9):1350-1357.

2. Takeuchi O, Akira S: Pattern recognition receptors and inflammation. Cell 2010, 140(6):805-820.

3. Kleinnijenhuis J, Oosting M, Joosten LA, Netea MG, Van Crevel R: Innate immune recognition of Mycobacterium tuberculosis. Clin Dev Immunol 2011, 2011:405310.

4. Saiga $H$, Shimada $Y$, Takeda K: Innate immune effectors in mycobacterial infection. Clin Dev Immunol 2011, 2011:347594.

5. Ma X, Liu Y, Gowen BB, Graviss EA, Clark AG, Musser JM: Full-exon resequencing reveals toll-like receptor variants contribute to human susceptibility to tuberculosis disease. PLoS One 2007, 2(12):e1318.

6. Schroder NW, Schumann RR: Single nucleotide polymorphisms of Toll-like receptors and susceptibility to infectious disease. Lancet Infect Dis 2005, 5(3):156-164.

7. Cuthbert AP, Fisher SA, Mirza MM, King K, Hampe J, Croucher PJ, Mascheretti S, Sanderson J, Forbes A, Mansfield J, Schreiber S, Lewis CM, Mathew CG: The contribution of NOD2 gene mutations to the risk and site of disease in inflammatory bowel disease. Gastroenterology 2002, 122(4):867-874.

8. Philpott DJ, Girardin SE: Nod-like receptors: sentinels at host membranes. Curr Opin Immunol 2010, 22(4):428-434.

9. Schreiber S, Rosenstiel P, Albrecht M, Hampe J, Krawczak M: Genetics of Crohn disease, an archetypal inflammatory barrier disease. Nat Rev Genet 2005, 6(5):376-388.

10. Strober W, Kitani A, Fuss I, Asano N, Watanabe T: The molecular basis of NOD2 susceptibility mutations in Crohn's disease. Mucosal Immunol 2008, 1(Suppl 1):S5-S9.

11. Hugot JP, Chamaillard M, Zouali H, Lesage S, Cezard JP, Belaiche J, Almer S, Tysk C, O'Morain CA, Gassull M, Binder V, Finkel Y, Cortot A, Modigliani R, Laurent-Puig P, Gower-Rousseau C, Macry J, Colombel JF, Sahbatou M, Thomas G: Association of NOD2 leucine-rich repeat variants with susceptibility to Crohn's disease. Nature 2001, 411(6837):599-603.

12. Ogura Y, Bonen DK, Inohara N, Nicolae DL, Chen FF, Ramos R, Britton H, Moran T, Karaliuskas R, Duerr RH, Achkar JP, Brant SR, Bayless TM, Kirschner BS, Hanauer SB, Nunez G, Cho JH: A frameshift mutation in NOD2 associated with susceptibility to Crohn's disease. Nature 2001, 411(6837):603-606.

13. Saleh M, Trinchieri G: Innate immune mechanisms of colitis and colitisassociated colorectal cancer. Nat Rev Immunol 2011, 11(1):9-20.

14. Holler E, Rogler G, Herfarth H, Brenmoehl J, Wild PJ, Hahn J, Eissner G, Scholmerich J, Andreesen R: Both donor and recipient NOD2/CARD15 mutations associate with transplant-related mortality and GvHD following allogeneic stem cell transplantation. Blood 2004, 104(3):889-894.

15. Holler E, Rogler G, Brenmoehl J, Hahn J, Greinix H, Dickinson AM, Socie G, Wolff D, Finke J, Fischer G, Jackson G, Rocha V, Hilgendorf I, Eissner G, Marienhagen J, Andreesen R: The role of genetic variants of NOD2/ CARD15, a receptor of the innate immune system, in GvHD and complications following related and unrelated donor haematopoietic stem cell transplantation. Int I Immunogenet 2008, 35(4-5):381-384.

16. van der Velden WJ, Blijlevens NM, Maas FM, Schaap NP, Jansen JH, van der Reijden BA, Feuth T, Dolstra H, Donnelly JP: NOD2 polymorphisms predict severe acute graft-versus-host and treatment-related mortality in T-cell-depleted haematopoietic stem cell transplantation. Bone Marrow Transplant 2009, 44(4):243-248.

17. Brenmoehl J, Herfarth H, Gluck T, Audebert F, Barlage S, Schmitz G, Froehlich D, Schreiber S, Hampe J, Scholmerich J, Holler E, Rogler G: Genetic variants in the NOD2/CARD15 gene are associated with early mortality in sepsis patients. Intensive Care Med 2007, 33(9):1541-1548.

18. Appenrodt B, Grunhage F, Gentemann MG, Thyssen L, Sauerbruch T, Lammert F: Nucleotide-binding oligomerization domain containing 2 (NOD2) variants are genetic risk factors for death and spontaneous bacterial peritonitis in liver cirrhosis. Hepatology 2010, 51(4):1327-1333.

19. Bruns T, Peter J, Reuken PA, Grabe DH, Schuldes SR, Brenmoehl J, Scholmerich J, Wiest R, Stallmach A: NOD2 gene variants are a risk factor for culture-positive spontaneous bacterial peritonitis and monomicrobial bacterascites in cirrhosis. Liver Int 2012, 32(2):223-230.

20. Fishbein T, Novitskiy G, Mishra L, Matsumoto C, Kaufman S, Goyal S, Shetty K, Johnson L, Lu A, Wang A, Hu F, Kallakury B, Lough D, Zasloff M: NOD2- expressing bone marrow-derived cells appear to regulate epithelial innate immunity of the transplanted human small intestine. Gut 2008 57(3):323-330.

21. Bruns T, Peter J, Hagel S, Pfeifer R, Prinz P, Stallmach A: Homozygous carrier of the NOD2 $1007 \mathrm{fs}$ frame-shift mutation presenting with refractory community-acquired spontaneous bacterial peritonitis and developing fatal pulmonary mucormycosis: A case report. Hepatol Res 2011, 41(10):1009-1014.

22. Azad AK, Sadee W, Schlesinger LS: Innate immune gene polymorphisms in tuberculosis. Infect Immun 2012, 80(10):3343-3359.

23. Zhao M, Jiang F, Zhang W, Li F, Wei L, Liu J, Xue Y, Deng X, Wu F, Zhang L, Zhang $X$, Zhang $Y$, Fan D, Sun $X$, Jiang T, Li JC: A novel single nucleotide polymorphism within the NOD2 gene is associated with pulmonary tuberculosis in the Chinese Han, Uygur and Kazak populations. BMC Infect Dis 2012, 12:91.

24. Zhang FR, Huang W, Chen SM, Sun LD, Liu H, Li Y, Cui Y, Yan XX, Yang HT, Yang RD, Chu TS, Zhang C, Zhang L, Han JW, Yu GQ, Quan C, Yu YX, Zhang Z, Shi BQ, Zhang LH, Cheng H, Wang CY, Lin Y, Zheng HF, Fu XA, Zuo XB, Wang $\mathrm{Q}$, Long $\mathrm{H}$, Sun YP, Cheng YL, et al: Genomewide association study of leprosy. N Engl J Med 2009, 361(27):2609-2618.

25. Pironi L, Joly F, Forbes A, Colomb V, Lyszkowska M, Baxter J, Gabe S, Hebuterne X, Gambarara M, Gottrand F, Cuerda C, Thul P, Messing B, Goulet O, Staun M, Van Gossum A: Long-term follow-up of patients on home parenteral nutrition in Europe: implications for intestinal transplantation. Gut 2011, 60(1):17-25.

26. Schaffler H, Schneider N, Hsieh CJ, Reiner J, Nadalin S, Witte M, Konigsrainer A, Blumenstock $\mathrm{G}$, Lamprecht $\mathrm{G}$ : NOD2 mutations are associated with the development of intestinal failure in the absence of Crohn's disease. Clin Nutr 2013.

27. Bozzetti F, Mariani L, Bertinet DB, Chiavenna G, Crose N, De Cicco M, Gigli G, Micklewright A, Moreno Villares JM, Orban A, Pertkiewicz M, Pironi L, Vilas $M P$, Prins F, Thul P: Central venous catheter complications in 447 patients on home parenteral nutrition: an analysis of over 100.000 catheter days. Clin Nutr 2002, 21(6):475-485

28. Howard L, Ashley C: Management of complications in patients receiving home parenteral nutrition. Gastroenterology 2003, 124(6):1651-1661.

29. Muller C, Schumacher U, Gregor M, Lamprecht G: How immunocompromised are short bowel patients receiving home parenteral nutrition? Apropos a case of disseminated Fusarium oxysporum sepsis. JPEN J Parenter Enteral Nutr 2009, 33(6):717-720.

30. Girardin SE, Boneca IG, Viala J, Chamaillard M, Labigne A, Thomas G, Philpott DJ, Sansonetti PJ: Nod2 is a general sensor of peptidoglycan through muramyl dipeptide (MDP) detection. J Biol Chem 2003, 278(11):8869-8872.

31. McGovern DP, van Heel DA, Ahmad T, Jewell DP: NOD2 (CARD15), the first susceptibility gene for Crohn's disease. Gut 2001, 49(6):752-754.

32. Guerra JF, Zasloff M, Lough D, Abdo J, Hawksworth J, Mastumoto C, Girlanda R, Island E, Shetty K, Kaufman S, Fishbein T: Nucleotide oligomerization domain 2 polymorphisms in patients with intestinal failure. J Gastroenterol Hepatol 2013, 28(2):309-313.

33. Ferwerda $G$, Girardin $S E$, Kullberg BJ, Le Bourhis $L$, de Jong DJ, Langenberg DM, van Crevel R, Adema GJ, Ottenhoff TH, Van der Meer JW, Netea MG: NOD2 and toll-like receptors are nonredundant recognition systems of Mycobacterium tuberculosis. PLoS Pathog 2005, 1(3):279-285.

34. Austin CM, Ma X, Graviss EA: Common nonsynonymous polymorphisms in the NOD2 gene are associated with resistance or susceptibility to tuberculosis disease in African Americans. J Infect Dis 2008, 197(12):1713-1716.

35. Moller M, Nebel A, Kwiatkowski R, van Helden PD, Hoal EG, Schreiber S: Host susceptibility to tuberculosis: CARD15 polymorphisms in a South African population. Mol Cell Probes 2007, 21(2):148-151.

36. Singh V, Gaur R, Mittal M, Biswas SK, Das R, Girdhar BK, Bajaj B, Katoch VM, Kumar A, Mohanty KK: Absence of nucleotide-binding oligomerization domain-containing protein 2 variants in patients with leprosy and tuberculosis. Int I Immunogenet 2012, 39(4):353-356.

\section{doi:10.1186/1471-230X-14-43}

Cite this article as: Schäffler et al:: Two patients with intestinal failure requiring home parenteral nutrition, a NOD2 mutation and tuberculous lymphadenitis. BMC Gastroenterology 2014 14:43. 